\title{
HIV and HCV health beliefs in an inner-city community
}

\author{
K. Krauskopf, ${ }^{1}$ T. G. McGinn, ${ }^{1}$ A. D. Federman, ${ }^{1}$ E. A. Halm, ${ }^{2}$ H. Leventhal, ${ }^{3}$ L. K. McGinn, ${ }^{4}$ \\ D. Gardenier, ${ }^{1}$ A. Oster ${ }^{5}$ and I. M. Kronish ${ }^{1}{ }^{1}$ Division of General Internal Medicine, Mount Sinai School of Medicine, New \\ York, NY; ${ }^{2}$ Division of General Internal Medicine, University of Texas Southwestern Medical Center, Dallas, TX; ${ }^{3}$ Institute of Health, Health Care Policy \\ and Aging Research, Rutgers, The State University of New Jersey, New Brunswick, NJ; ${ }^{4}$ Ferkauf Graduate School of Psychology, Yeshiva University, \\ Albert Einstein College of Medicine, New York, NY; and ${ }^{5}$ Charles B. Wang Community Health Center, New York, NY, USA
}

Received June 2010; accepted for publication July 2010

SUMMARY. Chronic infection with the hepatitis $\mathrm{C}$ virus (HCV) is more prevalent than human immunodeficiency virus (HIV) infection, but more public health resources are allocated to HIV than to HCV. Given shared risk factors and epidemiology, we compared accuracy of health beliefs about HIV and HCV in an at-risk community. Between 2002 and 2003, we surveyed a random patient sample at a primary care clinic in New York. The survey was organized as domains of Common Sense Model of Self-Regulation: causes ('sharing needles'), timeline/consequences ('remains in body for life', 'causes cancer') and controllability ('I can avoid this illness', 'medications may cure this illness'). We compared differences in accuracy of beliefs about HIV and HCV and used multivariable linear regression to identify factors associated with relative accuracy of beliefs. One hundred and twenty-two subjects completed the survey (response rate $42 \%)$. Mean overall health belief accuracy was 12/15 questions (80\%) for HIV vs 9/15 (60\%) for HCV $(P<0.001)$.
Belief accuracy was significantly different across all domains. Within the causes domain, $60 \%$ accurately believed sharing needles a risk factor for $\mathrm{HCV}$ compared to $92 \%$ for HIV $(P<0.001)$. Within the timeline/consequences domain, $42 \%$ accurately believed HCV results in lifelong infection compared to $89 \%$ for HIV $(P<0.001)$. Within the controllability domain, $25 \%$ accurately believed that there is a potential cure for HCV. Multivariable linear regression revealed female gender as significantly associated with greater health belief accuracy for HIV. Thus, study participants had significantly less accurate health beliefs about HCV than about HIV. Targeting inaccuracies might improve public health interventions to foster healthier behaviours and better hepatitis $\mathrm{C}$ outcomes.

Keywords: attitudes and practice, health beliefs, health knowledge, hepatitis C virus, human immunodeficiency virus.
Human immunodeficiency virus (HIV) and hepatitis C virus (HCV) cause two of the most common chronic blood-borne infections in the United States. Over one million people in the United States are living with HIV, and an even greater number, approximately 2.7-3.9 million, are chronically infected with HCV [1-3]. While HIV is transmitted through contact with bodily fluids (semen, vaginal fluid and breast milk), both diseases are transmitted by direct contact with infected blood. As a result, HIV and HCV share risk factors - most notably injection drug use. Consequently, these diseases are also linked through common epidemiological features.

\footnotetext{
Abbreviations: HCV, hepatitis C virus; HIV, human immunodeficiency virus.

Correspondence: Katherine Krauskopf, MD, Fellow, Division of General Internal Medicine, Mount Sinai School of Medicine, One Gustave L. Levy Place, Box 1087, New York, NY 10029, USA. E-mail: Katherine.Krauskopf@mssm.edu
}

However, while the age-adjusted HIV death rate has been decreasing or stabilizing in the United States since the mid1990 s, the number of deaths caused by HCV is projected to increase two to fourfold over the next two decades [4,5]. Fewer public health resources have been directed at HCV when compared to HIV, and prior studies suggest that at-risk communities lack awareness about HCV [3]. In combination with improved biological and behavioural treatments aimed at these viruses and at behaviours such as addiction that increase their risk of being acquired, educational programmes are needed to increase awareness and promote better health behaviours related to both viruses, especially HCV. Understanding current health beliefs held by at-risk populations might be the first step in designing programmes to increase awareness and knowledge regarding both diseases.

A growing body of literature demonstrates that patients' beliefs about diseases influence their health behaviours [6-8]. Stigma associated with injection drug use, limited access to health services for injection drug users, and limited 


\section{K. Krauskopf et al.}

federal and public health funding for HCV-related services in general may all contribute to inaccurate beliefs about HCV. In comparison, the stigma around HIV testing and treatment has diminished significantly over time, and government resources for medical and public health support around HIV are well-established. Thus, in spite of important similarities between HCV and HIV, it is likely that at-risk populations have less accurate beliefs about HCV when compared to HIV. Understanding and comparing health beliefs about HIV and HCV may be useful in identifying erroneous beliefs most in need of modification, to improve health outcomes in these populations. The Leventhal Common Sense Self-Regulation Model has been used to understand health beliefs about common chronic conditions like asthma, hypertension, heart failure and diabetes [7,9-11]. Less has been done regarding use of the Self-Regulation model as a means of assessing health beliefs about chronic infectious diseases such as HCV and HIV. According to the Common Sense Model, individuals develop health beliefs through personal illness episodes and socio-cultural associations that can be organized into five interconnected domains: (i) identity (the label ascribed to a condition and its associated symptoms), (ii) cause (based on both biomedical and nonscientific sources), (iii) temporal features or time-line (disease rate of onset, symptom duration as acute or chronic), (iv) consequences (impacts of a disease, including physical, psychological and social) and (v) controllability or curability (the degree to which a disease may be treated or controlled) [12,13].

To date, a handful of studies evaluate or compare lay understanding (knowledge, beliefs or attitudes) of HIV and $\mathrm{HCV}$ in the general population or in at-risk communities (injection drug users, for example). These studies suggest that the public has variable understanding of these infections and that beliefs tend to be more concordant with the biomedical model for HIV than for HCV [14-21]. At present, we are not aware of studies that formally compare health beliefs about HIV and HCV in the United States using a theory-based model of health beliefs.

To characterize and contrast health beliefs about HIV and $\mathrm{HCV}$, we surveyed patients using questions structured according to the Common Sense Model. We targeted patients from an at-risk, inner-city community where rates of HCV and HIV are disproportionately high. We hypothesized that despite the greater prevalence of HCV over HIV, health beliefs about HCV would be less accurate than beliefs about HCV [22,23].

\section{METHODS}

Our study population was comprised of patients attending an adult internal medicine clinic affiliated with a large academic medical centre in the East Harlem neighbourhood of New York City. East Harlem has the second highest AIDS case rate in the United States (36.6 per 100000 population) and the highest HCV infection rate in New York City (451.1/
100000 population) $[1,2,24,25]$. All patients seen in the clinic between April 2002 and November 2003 for a scheduled visit with a provider or for an unscheduled visit for an urgent problem were eligible for this study. Potential subjects were randomly selected from this population as they presented to clinic and offered participation by bilingual research assistants. Exclusion criteria included age younger than 18 years and primary language other than English or Spanish. The study protocol was approved by the Mount Sinai School of Medicine Institutional Review Board, and all patients signed informed consent prior to study participation.

Participants were surveyed about their health beliefs regarding HIV and HCV through face-to-face interviews conducted by trained, bilingual research assistants. The survey consisted of 15 'yes' or 'no' items (Table 1). Survey items were organized into the three domains relevant to the Common Sense Model: (i) causes, (ii) timeline/consequences and (iii) curability/controllability. Examples of survey items included: 'this illness may be caused by sharing needles' (causes domain), 'this illness may remain in the body for life' (timeline/consequences domain) and 'medications may cure this illness' (curability/controllability domain).

Table 1 Health beliefs survey with answers scored as accurate

\begin{tabular}{|c|c|c|}
\hline \multirow[b]{2}{*}{ Belief domain } & \multicolumn{2}{|c|}{$\begin{array}{l}\text { Accurate } \\
\text { statement }\end{array}$} \\
\hline & HIV & $\mathrm{HCV}$ \\
\hline \multicolumn{3}{|l|}{ Causes } \\
\hline \multicolumn{3}{|l|}{ This illness may be caused by } \\
\hline Eating contaminated food & No & No \\
\hline Shaking hands & No & No \\
\hline Being coughed on & No & No \\
\hline Sharing needles & Yes & Yes \\
\hline A virus & Yes & Yes \\
\hline Stress & No & No \\
\hline \multicolumn{3}{|l|}{ Timeline/consequences } \\
\hline \multicolumn{3}{|l|}{ This illness } \\
\hline $\begin{array}{l}\text { Usually causes problems that last only } \\
\text { a short time }\end{array}$ & No & No \\
\hline May cause problems that last many years & Yes & Yes \\
\hline May remain in the body for life & Yes & Yes \\
\hline May never cause problems & No & Yes \\
\hline May cause problems only after many years & Yes & Yes \\
\hline May cause cancer & Yes & Yes \\
\hline \multicolumn{3}{|l|}{ Curability/controllability } \\
\hline \multicolumn{3}{|l|}{ Regarding this condition } \\
\hline $\begin{array}{l}\text { There are things I can do to avoid } \\
\text { developing this illness }\end{array}$ & Yes & Yes \\
\hline Medications may cure this illness & No & Yes \\
\hline Vaccines can prevent this illness & No & No \\
\hline
\end{tabular}

HIV, human immunodeficiency virus; HCV, hepatitis C virus. 
Information regarding participants' sociodemographic status, exposure to HIV and HCV, and risk factors for both illnesses was also obtained through patient interview.

Our first study outcome was accuracy of health beliefs. We determined the accuracy of participants' health beliefs about HIV and HCV according to whether survey responses were concordant with the accepted biomedical models for each disease. For example, an answer of 'yes' to the survey item: 'this illness may be caused by sharing needles' would have been considered an accurate health belief for both HIV and HCV. We next summed the number of accurate survey items and generated accuracy percentages for each survey item, each domain and each disease overall. Our second outcome was the difference in these health belief accuracy percentages between HIV and HCV. We used the paired $t$ test to compare HIV and HCV health beliefs by assessing for significant differences in the accuracy across individual health beliefs and for differences in health belief accuracy across individual Common Sense Model domains and overall. Differences were considered significant at a $P$ value $<0.05$. Participants who reported a history of a positive blood test for HIV or HCV were excluded from our analyses (zero for HIV and five (4.1\%) for $\mathrm{HCV}$ ) as these participants were expected to have distinct health beliefs based on their differing personal histories with the conditions.

We performed an exploratory analysis to determine factors significantly associated with overall health belief accuracy for HIV and for HCV. Univariate analyses were performed using the paired $t$ test, Pearson's correlation and ANOVA depending on the characteristics of the variables. Linear regression was then used to assess the multivariable association between overall health belief accuracy and independent variables, as well as those variables with a $P$ value $<0.05$ for their association with overall health belief accuracy on univariate analysis. Independent variables included in our linear regression models were baseline sociodemographics (age, race, primary spoken language, insurance status and education level); personal risk factors for HIV and HCV (history of sexually transmitted infection, history of illicit drug use, history of sex without a condom with a person at risk for HCV); and knowledge of someone with HIV and/or HCV. These predictor variables were selected a priori and were chosen to identify potential targets for interventions to improve belief accuracy regarding HCV and HIV. All analyses were conducted using SPSS version 16 (IBM Company, Chicago, IL, USA).

\section{RESULTS}

We approached 288 clinic patients and 122 agreed to participate for a response rate of $42 \%$. Characteristics of the survey participants are provided in Table 2. The mean age was 46 years, $78 \%$ were women and $88 \%$ self-identified as nonwhite (Latino or Hispanic, African American and/or
Table 2 Demographic characteristics of respondents

\begin{tabular}{lc}
\hline Characteristics & $n=122$ \\
\hline Age, mean (SD), years & $45.8(14.0)$ \\
Race, \% & \\
$\quad$ White & 12.3 \\
$\quad$ Nonwhite & 87.7 \\
Gender, \% & \\
$\quad$ Female & 78.0 \\
Language, \% & \\
$\quad$ English & 79.5 \\
Insurance coverage, \% & \\
$\quad$ Medicaid & 54.1 \\
$\quad$ Other & 45.9 \\
Level of education, \% & \\
$\quad$ Grades 0-9 & 20.8 \\
$\quad$ Grades 10-12 & 42.5 \\
$\quad$ >12th grade & 36.7 \\
HCV infected ever, \% & 4.1 \\
HIV infected, \% & 0.0 \\
Know someone with HCV infection, \% & 19.7 \\
Know someone with HIV infection, \% & 42.6 \\
IDU ever, \% & 5.7 \\
Cocaine use ever, \% & 14.8 \\
> 50 lifetime sexual partners, \% & 7.4 \\
Unprotected sex ever with partner with & 14.8 \\
known behavioural risk factors, \% & \\
\hline
\end{tabular}

$\mathrm{HCV}$, hepatitis C virus; HIV, human immunodeficiency virus; IDU, injection drug use.

Black). Slightly more than half were Medicaid recipients. Eighty per cent had at least some high school-level education. Six per cent of participants reported a history of injection drug use and 15\% reported having either injected or inhaled cocaine. Overall, $43 \%$ of participants knew someone with HIV and $20 \%$ knew someone with HCV.

\section{Health belief accuracy}

Causes/risk factors

Almost all participants (92\%) accurately believed sharing needles is a risk factor for HIV, compared to only $60 \%$ who accurately believed sharing needles is a risk for $\mathrm{HCV}$ $(P<0.001)$ (Table 3).

\section{Timeline/consequences}

Most participants accurately believed that HIV infection could cause long-term problems $(84 \%)$ or remain in the body for life $(89 \%)$. In contrast, significantly fewer participants accurately believed the same for $\mathrm{HCV}$ (58\% and $42 \%$, respectively, $P<0.05)$. Fewer than $25 \%$ of participants accurately believed that HIV or HCV could result in cancer as a long-term consequence of either infection $(23 \%$ and $21 \%$ respectively, $P=0.73)$. 


\section{K. Krauskopf et al.}

Table 3 Health belief accuracy, mean per cent, HIV vs HCV

\begin{tabular}{|c|c|c|c|c|}
\hline \multirow[b]{2}{*}{ Belief domain } & \multirow[b]{2}{*}{ Health belief } & \multicolumn{3}{|c|}{$\%$ Participants with accurate belief } \\
\hline & & Regarding HIV & Regarding HCV & $P$ value \\
\hline \multirow[t]{7}{*}{ Causes } & This illness may be caused by & & & \\
\hline & Eating contaminated food & 92.3 & 76.1 & $<0.001$ \\
\hline & Shaking hands & 98.3 & 93.2 & 0.01 \\
\hline & Being coughed on & 90.6 & 85.5 & 0.13 \\
\hline & Sharing needles & 91.5 & 59.8 & $<0.001$ \\
\hline & A virus & 53.9 & 28.2 & $<0.001$ \\
\hline & Stress & 97.4 & 97.4 & 1.000 \\
\hline \multirow{7}{*}{ Timeline/consequences } & This illness & & & \\
\hline & Usually causes problems that last only a short time & 100.0 & 91.0 & 0.001 \\
\hline & May cause problems that last many years & 83.8 & 58.1 & $<0.001$ \\
\hline & May remain in the body for life & 88.9 & 41.9 & $<0.001$ \\
\hline & May never cause problems & 94.9 & 6.0 & $<0.001$ \\
\hline & May cause problems only after many years & 40.2 & 40.2 & 1.000 \\
\hline & May cause cancer & 23.0 & 21.4 & 0.73 \\
\hline \multirow{4}{*}{ Curability/controllability } & Regarding this condition & & & \\
\hline & There are things I can do to avoid this illness & 85.5 & 68.4 & $<0.001$ \\
\hline & Medications may cure this illness & 92.3 & 24.8 & $<0.001$ \\
\hline & Vaccines can prevent this illness & 93.2 & 78.6 & 0.001 \\
\hline
\end{tabular}

HIV, human immunodeficiency virus; $\mathrm{HCV}$, hepatitis $\mathrm{C}$ virus.

\section{Curability/controllability}

Significantly, more participants accurately believed that they could take measures to avoid contracting HIV when compared to HCV ( $86 \%$ and $68 \%$, respectively, $P<0.001)$. The majority of participants (92\%) accurately believed that medications would not cure HIV. In contrast, only one quarter of participants accurately believed that medications could cure HCV (curative treatments were available for this infection at the time this study was conducted).

\section{Overall health beliefs}

By each health belief domain and for the survey overall, beliefs were significantly more accurate for HIV than for HCV (Table 4). Specifically, health belief accuracy for HIV

Table 4 Health belief accuracy by belief domain, HIV vs HCV

\begin{tabular}{|c|c|c|c|}
\hline & $\begin{array}{l}\% \text { participants } \\
\text { with accurate } \\
\text { beliefs, HIV }\end{array}$ & $\begin{array}{l}\% \text { participants } \\
\text { with accurate } \\
\text { beliefs, HCV }\end{array}$ & \\
\hline Belief domain & Mean & Mean & $P$ value \\
\hline Causes & 87.3 & 73.4 & $<0.001$ \\
\hline $\begin{array}{l}\text { Timeline } \\
\text { Consequences }\end{array}$ & 71.8 & 43.0 & $<0.001$ \\
\hline Controllability & 90.3 & 57.3 & $<0.001$ \\
\hline Overall & 81.7 & 58.0 & $<0.001$ \\
\hline
\end{tabular}

HIV, human immunodeficiency virus; HCV, hepatitis C virus. was greatest in the curability/controllability domain (90\%) and for HCV in the causes domain (73\%). Health beliefs for both diseases were the least accurate in the timeline/consequences domain.

Factors associated with overall health belief accuracy Linear regressions were performed for both HIV and HCV to determine any factors that might be associated with greater health belief accuracy for either disease. Only female gender was significantly associated with greater health belief accuracy and only in our adjusted model for $\operatorname{HIV}(P=0.02)$.

\section{DISCUSSION}

In this study of inner-city adults from a community at high risk for HIV and HCV, participants were more likely to have inaccurate health beliefs about risks factors for causes, sequelae and control of HCV than of HIV. Overall, our results demonstrate that study participants have accurate health beliefs for HCV only $58 \%$ of the time. Furthermore, as hypothesized, our study population demonstrated significantly less accurate health beliefs about HCV than about HIV, despite the fact that participants were recruited from a community with higher prevalence of HCV than of HIV. This discrepancy in health beliefs for the two infections was present for several key domains within the Common Sense Model.

Results of our study also highlight specific health belief inaccuracies that might be important targets for public health interventions. When compared to HIV, fewer 
participants accurately believed that HCV could be prevented, fewer believed that HCV could be transmitted by sharing needles, and less than half accurately believed that it is a potentially life-long infection. The fact that beliefs were more accurate for HIV than for HCV in our study suggests that lessons might be learned from successful HIV interventions to improve similar health beliefs about the risk for and long-term consequences of HCV.

In contrast with HIV that cannot yet be cured, HCV treatments are curative (defined as sustained viral response 6 months after completing treatment). While treatment with pegylated interferon and ribavirin is involved and often arduous, a sustained viral response can be obtained in 40$80 \%$ of treated cases of chronic HCV, depending on viral genotype and certain patient characteristics. Furthermore, the advent of new therapies suggests that cure rates may rise in the near future. Yet, only $25 \%$ of our study participants believed there to be a potential cure for HCV infection. In general, low uptake of HCV treatment poses a persistent challenge - despite the possibility of SVR, 20-30\% of patients with HCV initiate and complete therapy [26,27]. The decision to initiate treatment for HCV is complex and health beliefs may pose an important component. The commonly held belief among patients in our study that HCV is not curable may stem in part from limited knowledge about treatment options. It is also possible that treatment side effects or treatment failures have been disproportionately represented in our survey community, thus contributing to the belief that HCV is not curable.

A number of additional associations deserve comment. First, only one quarter of our survey participants accurately believed that both HIV and HCV can cause cancer. These are concerning results as HCV continues to represent the leading cause of liver transplantation in the United States, contributing significantly to growing rates of cirrhosis and hepatocellular carcinoma [28]. Similarly, since the advent of HAART, rates of cancer - in particular non-AIDS malignancies - continue to rise in the HIV-infected population $[29,30]$. It may be difficult for individuals to modify perceptions of HIV and HCV as infectious diseases that are capable of resulting in long-term, even chronic, health consequences. Interventions to improve health beliefs about HIV and HCV might highlight the growing overlap of infectious disease elements with long-term, chronic disease characteristics within these illnesses. Helping patients understand that engaging in healthier behaviours related to HIV and HCV may prevent not just the infection, but also the development of chronic disease and cancer, may prove to be a compelling public health strategy. Sylvestre et al. [31], for example, have demonstrated that peer-based educational interventions have successfully engaged members of an urban community of drug users in care, with subsequent increases in $\mathrm{HCV}$ testing and treatment uptake. Broader application of these techniques might serve to improve health beliefs and HCV health outcomes in additional at-risk communities.
Second, the association between female gender and accurate health beliefs about HIV deserves some exploration. Perhaps this association reflects the fact that women, more often then men, participate in the health care system and in accessing community-based health information - either in caring for themselves or as caregivers for others [32-34]. As a result, women may come into contact more often with accurate health information, may be more motivated themselves to seek screening and treatment in general, and may be more likely to encounter others seeking screening and treatment for HIV. These factors may subsequently contribute to more accurate HIV health beliefs.

To our knowledge, at present there are no studies formally comparing health beliefs about HIV and HCV in an at-risk community in the United States, using the Self-Regulation model. Several limitations of our study are worth noting. The overall sample size and response rate were modest. Yet the sociodemographics of participants in our study were representative of the clinic population in general, and the high rate of Medicaid insurance was reflective of the study community at large. In addition, our study was conducted in a single, hospital-based, academic internal medicine practice, and findings should therefore be interpreted carefully in the context of other settings. Interviews for this study were conducted in-person, which may have resulted in some response bias because of the highly personal and sensitive nature of some of the survey questions. Less-public approaches to asking them, such as audio computer assisted self-interviews, might have been more effective at eliciting some participants' health beliefs. In addition, 'history of sex without a condom with a person at risk for HCV' was included as an independent variable in our regression model. Use of this variable as a predictor is ambiguous, as evidence in the time period since this study was conducted demonstrates that HCV is not a sexually transmitted infection in the traditional sense, given that its mode of transmission is blood borne. Finally, our study suggests that further research might explore health beliefs compared to health knowledge in a similar population.

Prominent public health messages about HIV appear to have largely been received and remembered by this at-risk population. This does not appear to have been the case with HCV in this same population, despite shared risk factors. This deficit, therefore, is likely not due to underlying low health literacy of this population. Instead, it may reflect that our study population has not been effectively exposed to detailed HCV public health messages or that these messages simply do not exist. As Klein et al. describe, despite the creation of the National Hepatitis C Prevention Strategy in 2001, federal funding for HCV in the United States through the Centers for Disease Control and Prevention Division of Viral Hepatitis has been limited to supporting HCV coordinators on a State level. Thus, federal funding has not been sufficient for the development of sustainable $\mathrm{HCV}$ public health prevention programmes or services implementation [35]. 
Furthermore, if $\mathrm{HCV}$ public health messages have been created on a local level, they may not have effectively connected with our study population. As the burden of HCV infection continues to mount in the United States and promising new therapies become available to combat it, screening and treatment must increase beyond their current, disappointingly low rates. The Institute of Medicine recently acknowledged this need when it issued its Report on Hepatitis Prevention and Control, which recommends the development of national public health strategies to improve awareness of HCV in at-risk communities and in the general population [3]. Disseminating accurate information about HCV may be a key element to modifying patient behaviour and may subsequently result in better health outcomes for patients. Educational efforts should extend beyond providing correct health information to improve knowledge and should also address specific socio-cultural experiences that influence the development of health beliefs to perhaps foster healthier behaviours.

\section{REFERENCES}

1 Cases of HIV infection and AIDS in the United States and Dependent Areas, 2007 HIV/AIDS Surveillance Report, Volume 19. Available at: http://www.cdc.gov/hiv/topics/ surveillance/resources/reports/2007report/pdf/2007Surveil lanceReport.pdf (accessed 30 September 2009).

2 Kaiser Family Foundation HIV/AIDS Policy Fact Sheet. Available at: http://www.kff.org/hivaids/upload/Fact-SheetThe-HIV-AIDS-Epidemic-in-the-United-States-2005-Update. pdf (accessed 25 November 2009).

3 Hepatitis and Liver Cancer: A National Strategy for Prevention and Control of Hepatitis B and C. Colvin HM, Mitchell AE, eds. Committee on the Prevention and Control of Viral Hepatitis Infections, Institute of Medicine, 2009.

4 Volk ML, Tocco R, Saini S, Lok ASF. Public health impact of antiviral therapy for hepatitis C in the United States. Hepatology 2009; 50(6): 1750-1755.

5 CDC HIV mortality slides. Available at: http://www.cdc.gov/ hiv/topics/surveillance/resources/slides/mortality/slides/mor tality.pdf (accessed 20 December 2009).

6 Halm EA, Mora P, Leventhal H. No symptoms, no asthma: the acute episodic disease belief is associated with poor selfmanagement among inner-city adults with persistent asthma. Chest 2006; 129(3): 573-580.

7 Horne R, Clatworthy J, Polmear A, Weinman J. Do hypertensive patients' beliefs about their illness and treatment influence medication adherence and quality of life? J Hum Hypertens 2001; 15(Suppl 1): S65-S68.

8 Horowitz CR, Rein SB, Leventhal H. A story of maladies, misconceptions and mishaps: effective management of heart failure. Soc Sci Med 2004; 58(3): 631-643.

9 Brewer NT, Chapman GB, Brownlee S, Leventhal EA. Cholesterol control, medication adherence and illness cognition. Br J Health Psychol 2002; 4: 433-447.

10 Horne R, Weinman J. Patients' beliefs about prescribed medicines and their role in adherence to treatment in chronic physical illness. J Psychosom Res 1999; 47(6): 555-567.

11 Mann DM, Ponieman D, Leventhal H, Halm EA. Predictors of adherence to diabetes medications: the role of disease and medication beliefs. J Behav Med 2009; 32(3): 278-284.

12 Leventhal H, Brissette I, Leventhal E. The Common Sense Models of Self-regulation of Health and Illness. London: Taylor \& Francis Books, Ltd, 2003.

13 Reynolds NR. The problem of antiretroviral adherence: a self-regulatory model for intervention. AIDS Care 2003; 15(1): 117-124.

14 Sastre MT, Monsirmen S, Morin G et al. Changes in French people's misconceptions about hepatitis C, 1997-2003. Prev Med 2006; 42(2): 150-153.

15 Walley AY, White MC, Kushel MB, Song YS, Tulsky JP. Knowledge of and interest in hepatitis $\mathrm{C}$ treatment at a methadone clinic. J Subst Abuse Treat 2005; 28(2): 181-187.

16 Racz J, Gyarmathy VA, Neaigus A, Ujhelyi E. Injecting equipment sharing and perception of HIV and hepatitis risk among injecting drug users in Budapest. AIDS Care 2007; 19(1): 59-66.

17 Canfield KM, Smyth E, Batki SL. Methadone maintenance patients' knowledge, attitudes, beliefs, and experiences concerning treatment for hepatitis C virus infection. Subst Use Misuse 2010; 45(4): 496-514.

18 Goldberg RW, Tapscott SL, Calmes CA, Wolfe RS. HIV and hepatitis C knowledge among individuals with serious mental illness. Psychiatr Rehabil J 2009; 33(1): 47-49.

19 Heimer R, Clair S, Grau LE, Bluthenthal RN, Marshall PA, Singer M. Hepatitis-associated knowledge is low and risks are high among HIV-aware injection drug users in three US cities. Addiction 2002; 97(10): 1277-1287.

20 Lally MA, Montstream-Quas SA, Tanaka S, Tedeschi SK, Morrow KM. A qualitative study among injection drug using women in Rhode Island: attitudes toward testing, treatment, and vaccination for hepatitis and HIV. AIDS Patient Care STDS 2008; 22(1): 53-64.

21 Strauss JL, Bosworth HB, Stechuchak KM, Meador KM, Butterfield MI. Knowledge and risks of human immunodeficiency virus transmission among veterans with severe mental illness. Mil Med 2006; 171(4): 325-330.

22 Frieden TR. The State of HIV/AIDS in NYC... and What We Need to Do to Stop the Epidemic. New York City Department of Health and Mental Hygiene, 3/17/2006.

23 National Center for HIV/AIDS, Viral Hepatitis, STD, and TB Prevention. Annual Report, Fiscal Year 2008. Available at: http://www.cdc.gov/NCHHSTP/docs/NCHHSTP-AnnualReport-508c.pdf (accessed 28 May 2010).

24 New York City HIV/AIDS Annual Surveillance Statistics. New York: New York City Department of Health and Mental Hygiene, 2007. Updated November 27, 2007. Available at: http://www.nyc.gov/html/doh/html/ah/hivtables.shtml (accessed 30 September 2009).

25 New York City Department of Health and Mental Hygiene, Division of Disease Control, Bureau of Communicable Diseases. Hepatitis A, B and C Surveillance Report. New York City, 2005. Available at: http://www.nyc.gov/html/doh/ downloads/pdf/cd/cd-hepabc-surveillance-report.pdf (accessed 30 September 2009). 
26 Mehta SH, Genberg BL, Astemborski J et al. Limited uptake of hepatitis C treatment among injection drug users. J Community Health 2008; 33(3): 126-133.

27 Grebely J, Raffa JD, Lai C et al. Low uptake of treatment for hepatitis $\mathrm{C}$ virus infection in a large community-based study of inner city residents. J Viral Hepat 2009; 16(5): 352-358.

28 Recommendations for Prevention and Control of Hepatitis C Virus (HCV) Infection and HCV-Related Chronic Disease. MMWR Recommendations and Reports. October 16, 1998/47 (RR19); 1-39. Available at: http://www.cdc.gov/ mmwr/preview/mmwrhtml/00055154.htm (accessed 30 September 2009).

29 Bedimo RJ, McGinnis KA, Dunlap M, Rodriguez-Barradas $\mathrm{MC}$, Justice AC. Incidence of non-AIDS-defining malignancies in HIV-infected versus noninfected patients in the HAART era: impact of immunosuppression. J Acquir Immune Defic Syndr 2009; 52(2): 203-208.

30 Shiels MS, Cole SR, Kirk GD, Poole C. A meta-analysis of the incidence of non-AIDS cancers in HIV-infected individuals. J Acquir Immune Defic Syndr 2009; 52(5): 611-622.
31 Sylvestre DL, Zweben JE. Integrating HCV services for drug users: a model to improve engagement and outcomes. Int $J$ Drug Policy 2007; 18(5): 406-410.

32 Mansfield AK, Addis ME, Courtenay W. Measurement of men's help seeking: development and evaluation of the barriers to help seeking scale. Psychol Men Masc 2005; 6(2): 95-108.

33 Galdas PM, Cheater F, Marshall P. Men and health helpseeking behaviour: literature review. J Adv Nurs 2005; 49(6): 616-623.

34 US Department of Health and Human Services, Office on Women's Health. Literature Review on Effective Sex- and Gender-Based Systems/Models of Care. Available at: http://www. womenshealth.gov/owh/multidisciplinary/reports/GenderBasedMedicine/Question1.cfm (accessed 16 March 2010).

35 Klein SJ, Flanigan CA, Cooper JG, Holtgrave DR, Carrascal AF, Birkhead GS. Wanted: an effective public health response to hepatitis $\mathrm{C}$ virus in the United States. J Public Health Manag Pract 2008; 14(5): 471-475. 